\title{
Experimental Kinetics of Infection Induced by Yersinia pseudotuberaulosis Isolated from Stock Animals
}

\author{
Carlos Henrique Gomes Martins/*/+ , Deise Pasetto Falcão*
}

Faculdade de Biomedicina, Universidade de Franca, Av. Dr. Armando Salles Oliveira 201, 14404-600 Franca, SP, Brasil

*Departamento de Ciências Biológicas, Faculdade de Ciências Farmacêuticas, Unesp, Araraquara, SP, Brasil

The course of in vivo infection of five isolates of Yersinia pseudotuberculosis was followed for three weeks in Swiss mice. The strains were isolated from diarrheic and normal feces and mesenteric lymph nodes of healthy and sick stock animals. Four strains of serogroup O:3 and one of serogroup O:1a, with and without the virulence plasmid, were inoculated intragastrically and intravenously in the mice. Groups of five animals were sacrificed at 6 $h$ and 3, 6, 10, 15, and 21 days after inoculation, and organs and tissues were checked for possible macroscopic alterations. Development of infection was monitored at these times by performing viable bacterial counts in homogenates of selected tissues. The animals were cheked daily for clinical alterations. The results of the study showed that strains with the virulence plasmid infected organs and tissues at various times and at varying intensity by both routes of infection, the strain of type O:1 a being the most invasive. Moreover, clinical and pathological alterations occurred only in animals inoculated with bacteria carrying the virulence plasmid, regardless of the route of infection.

Key words: Yersinia pseudotuberculosis - kinetics of infection - virulence

Yersinia pseudotuberculosis causes various clinical syndromes in men and animals. To induce disease, a set of virulence factors related to plasmid and chromosomal genes must be present, which contribute to host colonization and prevent the action of specific and nonspecific host defense mechanisms.

Pathogenic Y. pseudotuberculosis, like other pathogenic Yersinia species, harbors a plasmid of 70-75 kb, known as the Yersinia virulence plasmid pYV (Brubaker 1991). The products of the genes on this plasmid are grouped into four main categories: adhesion/invasion protein (YadA), antiphagocytic secreted proteins (Yops), proteins involved in Yop processing and secretion (Ysc), and regulatory proteins (Lcr) (Salyers \& Whitt 2002). Among the latter is the LcrF protein. Invasion protein (Inv) coded by chromosomal gene is also one of the virulence mechanisms of pathogenic Yersinia. Invasiveness is mediated by gene inv on the chromosome and gene yadA on the plasmid (Revell \& Miller 2001). Another very important characteristic of Yersinia virulence mediated by chromosomal genes is the ability to capture iron, which is regulated by a set of genes forming the high-pathogenicity island, HPI (Carniel 1999).

Interaction between bacteria and host cells is an important step in the establishment of infection. After intestinal colonization by pathogenic Yersinia, the bacteria penetrate the intestinal mucosa through the M cells. Af-

Financial support: Fundação de Amparo a Pesquisa do Estado de São Paulo, proc. 98/00984-9

${ }^{+}$Corresponding author. Fax: +55-16-3711-8873. E-mail: martinsc@unifran.br

Received 10 November 2003

Accepted 9 September 2004 ter penetration, Yersinia colonize Peyer's patches, possibly disseminating through the lymphatic pathway and eventually reaching the mesenteric lymph nodes, the liver, and the spleen (Grutzkau et al. 1990, Falkow et al. 1992, Clark et al. 1998).

The pathogenicity of Yersinia can be studied in vitro and in vivo; in vitro by searching for the different genes involved or their products and in vivo by experimental infection and monitoring its kinetics in animals such as mice, rats, rabbits or guinea pigs. The latter has been well documented in Y. enterocolitica (Quan et al. 1974, Carter \& Collins 1974, Alonso et al. 1975, 1978, Une 1977, Falcão et al. 1984, Apfel \& Noleto 1991, Bauab \& Falcão 1991, Heesemann et al. 1993). However in Y. pseudotuberculosis, only a few studies have shown in vivo infection, and the kinetics has not been studied.

Working with $Y$. pseudotuberculosis $\mathrm{O}: 3$ strains harboring the virulence plasmid and inoculated by the oral $\left(5 \times 10^{9}\right.$ bacteria/ml) and intraperitonial (from $10^{4}$ to $10^{7}$ bacteria/ml) routes in BALB/cJ mice, Holmström et al. (1995) observed systemic infection in all animals.

After inoculating guinea pigs by the respiratory route (in an aerosol chamber of the flow-dynamic type) with $Y$. pseudotuberculosis (nr 5763, Czechoslovac Collection), Veljanov et al. (1993) described the involvement of the lungs and tracheobronchial organs of animals in early infection, which later became generalized. The infectious process was monitored on the basis of the increased numbers of polymorphonuclear leukocytes and phagocytic activity.

After inoculating mice intraperitoneally $\left(10^{7}\right.$ organisms) with melibiose-fermenting and non-fermenting $Y$. pseudotuberculosis $0: 3$ strains isolated from healthy swine, Tsubokura et al. (1984) correlated the death of mice with the ability of the bacteria to ferment the carbohydrate. 
This study investigates the kinetics of infection induced in mice by $Y$. pseudotuberculosis strains with or without some plasmidial and chromosomal virulence markers.

\section{MATERIALS AND METHODS}

Bacterial strains - A total of five Y. pseudotuberculosis strains isolated from stock animals in Brazil were studied. Their previously determined characteristics (Martins et al. 1998), are shown in the Table.

Experimental infection - Performed according to Falcão et al. (1984).

For each experiment, 35 female Swiss mice aged five to six weeks were used. Bacteriologically-controlled animals were obtained from the Central Animal House of São Paulo State University (Unesp) at Botucatu. Groups of five animals were kept in disinfected cages with free access to previously sterilized food and water. To activate the virulence of the bacteria, $0.5 \mathrm{ml}$ of a $10^{8}$ cells $/ \mathrm{ml}$ saline suspension of the strain, grown in blood agar base for $24 \mathrm{~h}$ at $25^{\circ} \mathrm{C}$, was inoculated intravenously into two mice. After $24 \mathrm{~h}$, the animals were killed and their spleens removed. A saline homogenate of each spleen was poured on to blood agar base plates and incubated at $25^{\circ} \mathrm{C}$ for $48 \mathrm{~h}$. The growth on these plates was used to prepare the inoculum. A selected smooth colony was streaked on the surface of a blood agar base plate and incubated at $25^{\circ} \mathrm{C}$ for $24 \mathrm{~h}$. The resulting growth was harvested in $10 \mathrm{ml}$ of sterilized saline. Two suspensions were prepared from this material to obtain inocula with $10^{8}$ cells $/ \mathrm{ml}$ for intragastric inoculation (IG) and $10^{6}$ cells $/ \mathrm{ml}$ for intravenous (IV) inoculation (Falcão et al. 1984, Bauab \& Falcão 1991). Infection was induced either with a $0.5 \mathrm{ml}$ suspension $\left(10^{6}\right.$ cells $\left./ \mathrm{ml}\right)$ injected into the tail vein on with a $0.25 \mathrm{ml}$ suspension $\left(10^{8}\right.$ cells $/ \mathrm{ml}$ ) administered intragastrically.

Groups of five mice were sacrificed $6 \mathrm{~h}$ and $3,6,10,15$, and 21 days after inoculation. The remaining five mice were kept to complete the groups, in the case of death of animals before the end of the experiments on the 21st day. One-third of the cecum, the liver, spleen, and mesenteric lymph node chain were removed from each mouse, four Peyer's patches from the small intestine were excised and $0.5 \mathrm{ml}$ of blood was obtained by cardiac puncture. $0.1 \mathrm{ml}$ of the blood was immediately surface-plated on blood agar base.
The cecal content was homogenized in nutrient broth and all the others in saline. All homogenates were diluted in saline $\left(10^{-1}-10^{-3}\right)$. Peyer's patches were washed three times in cold saline prior to homogenization and dilution. A $0.1 \mathrm{ml}$ aliquot of each tenfold dilution in saline was surface-plated in duplicate on blood agar base. The colonyforming units were counted up to $48 \mathrm{~h}$ of incubation at $25^{\circ} \mathrm{C}$. Y. pseudotuberculosis colonies were confirmed by slide agglutination using specific antiserum.

Clinical and pathological alterations - During the entire experiment, live animals were observed daily for clinical alterations such as diarrhea, prostration, emaciation, ruffled hair, etc. After being killed, they were examined for lesions and other visible pathological manifestations.

\section{RESULTS}

The course of in vivo infection of each of the five strains of $Y$. pseudotuberculosis is represented graphically in Figs 1-5.

The Yp36 strain, of serogroup O:3 but without plasmid pYV, when inoculated by the IG route (Fig. 1), was found $6 \mathrm{~h}$ later in the cecal content and Peyer's patches, and 3 days later in the mesenteric ganglia as well as in the cecal content, but in smaller numbers than those detected after $6 \mathrm{~h}$ of infection. After IV inoculation (Fig. 1), these bacteria were isolated from Peyer's patches, spleen, liver, and blood during the first $6 \mathrm{~h}$ of infection and after 3 days from the spleen and liver, being present in smaller numbers in the liver than during the earlier period. Bacteria were not detected at any of the later times when animals were sacrificed or in the remaining organs, regardless of the route of inoculation.

Strain Yp94, also of serogroup O:3 and without pYV, when inoculated intragastrically (Fig. 2), was found in the cecal material of animals sacrificed $6 \mathrm{~h}$ and 3 and 6 days after infection, but in decreasing numbers at each subsequent time. The strain was also isolated from the spleen and liver of animals on the third day of infection. Six hours after IV inoculation (Fig. 2), Yp94 bacteria were isolated from the spleen, liver and blood, and 3 days after inoculation, they were isolated from the spleen in smaller numbers than at the earlier time. Like strain Yp36, strain Yp94 was not isolated from other organs or at any time (6, 10,15 and 21 days) after the third day.

TABLE

Characteristics of the Yersinia pseudotuberculosis strains studied

\begin{tabular}{|c|c|c|c|c|c|c|}
\hline Strain/bio-serogroups & $\mathrm{pYV}(\mathrm{kb})$ & Virulence markers $^{a}$ & Origin & Clinical material & Geographical origin & Year \\
\hline Yp36 (2/O:3) & No $p Y V$ & irp1, irp2 & Cattle & Diarrheic feces & Paraná & 1989 \\
\hline Yp94 (2/O:3) & No pYV & irp1, irp2 & Buffalo & Normal feces & Rio Grande do Sul & 1990 \\
\hline Yp32 (1/O:1a) & 79 & $\begin{array}{l}\text { lcrF, irp } 1, \text { irp } 2, p s n, \\
\text { IS } 100, y b t E, y b t X-y b t S \text {, } \\
y b t P-y b t Q\end{array}$ & Buffalo & $\begin{array}{l}\text { Mesenteric lymph } \\
\text { nodes }\end{array}$ & Rio Grande do Sul & 1989 \\
\hline Yp21 (2/O:3) & 79 & lcrF, $\operatorname{irp} 1, \operatorname{irp} 2$ & Swine & Diarrheic feces & Paraná & 1985 \\
\hline Yp61 (2/O:3) & 71 & $l c r F$, irpl, irp2 & Cattle & Diarrheic feces & Paraná & 1989 \\
\hline
\end{tabular}

pYV: virulence plasmid of Yersinia; $a$ : unpublished data, as described by Fukushima et al. (2001); lcrF: low calcium response gene; irp 1: iron-repressible protein 1 gene; irp2: iron-repressible protein 2 gene; $p s n$ : pesticin sensitivity gene; IS 100: insertion sequence gene; $y b t E$ : yersiniabactin $\mathrm{E}$ gene; $y b t X-y b t S$ : yersiniabactin $\mathrm{X}$ and $\mathrm{S}$ genes; $y b t P-y b t Q$ : yersiniabactin $\mathrm{P}$ and $\mathrm{Q}$ genes 

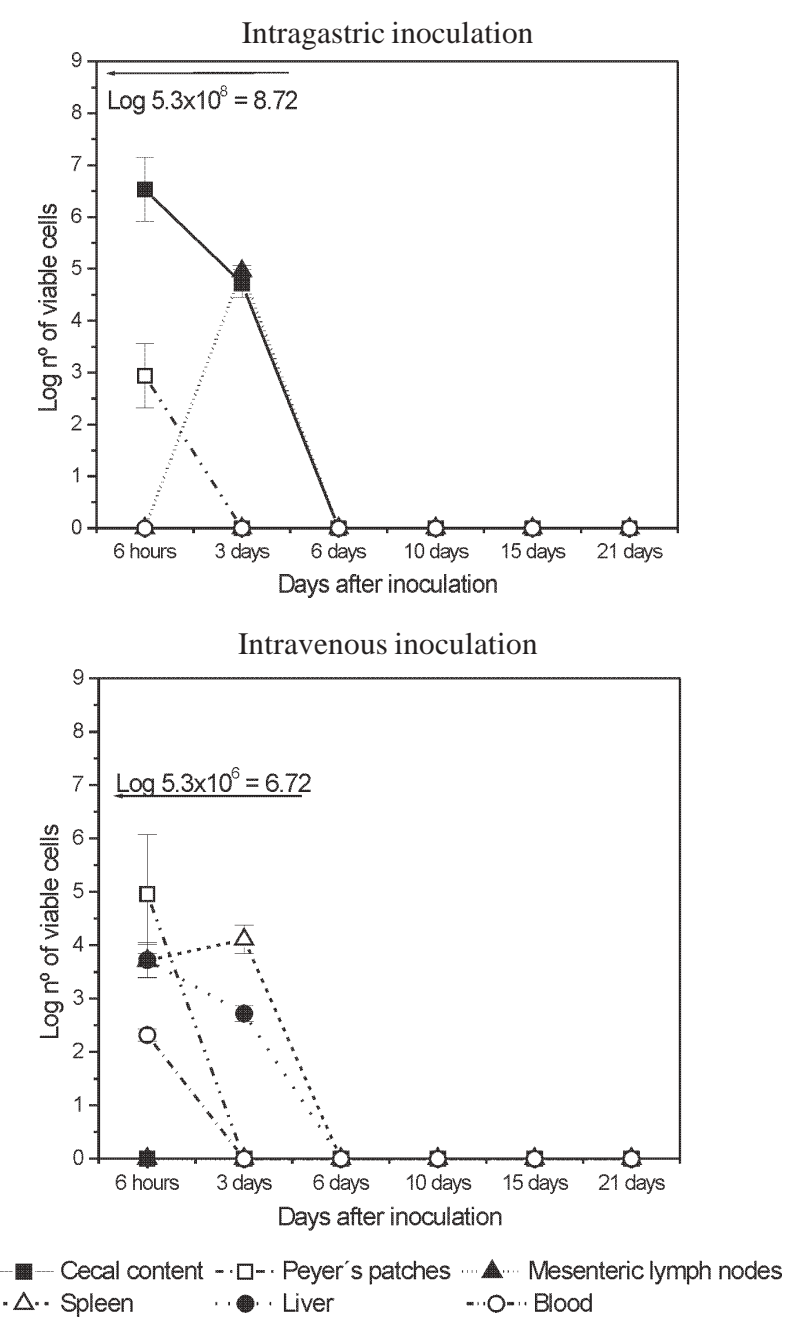

Fig. 1: experimental infection with strain Yp36: Yersinia pseudotuberculosis 2/O:3 not harboring the virulence plasmid and $\operatorname{lcr} F$ gene, but positive for irpl and irp2 genes, inoculated intragastrically and intravenously into female Swiss mice.

No clinical alterations or macroscopic lesions were observed in mice infected with strains Yp36 or Yp94.

The Yp32 strain of serogroup O:1a, which harbored the pYV plasmid, was the most virulent. After IG inoculation (Fig. 3), the strain was isolated from all organs after 6 $\mathrm{h}$ of infection, being undetectable only in the blood. The animals developed diarrhea between the 3rd and 6th day of infection and those sacrificed on the 6th day presented enlarged liver and spleen. Although they recovered from diarrhea after the 10th day of infection, four of them died during the experiment. After IV infection (Fig. 3), the experiment could only be continued to the 10th day, when the five surviving animals were sacrificed, the rest of the group of 35 having died before the 10th day. After $6 \mathrm{~h}$, as well as after 3 and 6 days of infection, bacteria had invaded all organs and tissues examined and were able to multiply in them. Clinical examination of the animals showed severe diarrhea with lesions in the various organs and increased Peyer's patch volume and enlarge- ment of the mesenteric ganglion chain.

After IG infection (Fig. 4), strain Yp21 of serogroup $\mathrm{O}: 3$, which harbors the pYV plasmid, was isolated from various organs up to the 15 th day of infection. The animals did not suffer diarrhea, but were apathetic during the 1 st days after infection, and four of them died. Those sacrificed on the 3rd day exhibited lesions in the liver. This strain showed greater aggressiveness after IV infection (Fig. 4), since no animal survived until the 21st day. The experiment was therefore finished on the 15th day, when all surviving animals were sacrificed. The bacterium infected all organs examined on the 3rd and 6th days after infection. After $6 \mathrm{~h}$, it was isolated from the spleen, liver and blood, and on the 15th day it was isolated from cecal content and Peyer's patches. The animals developed diarrhea, macroscopic lesions appeared in the liver and spleen and the volume of Peyer's patches increased.

When inoculated by the IG route (Fig. 5), the Yp61 strain of serogroup O:3, which also carried the pYV plas-
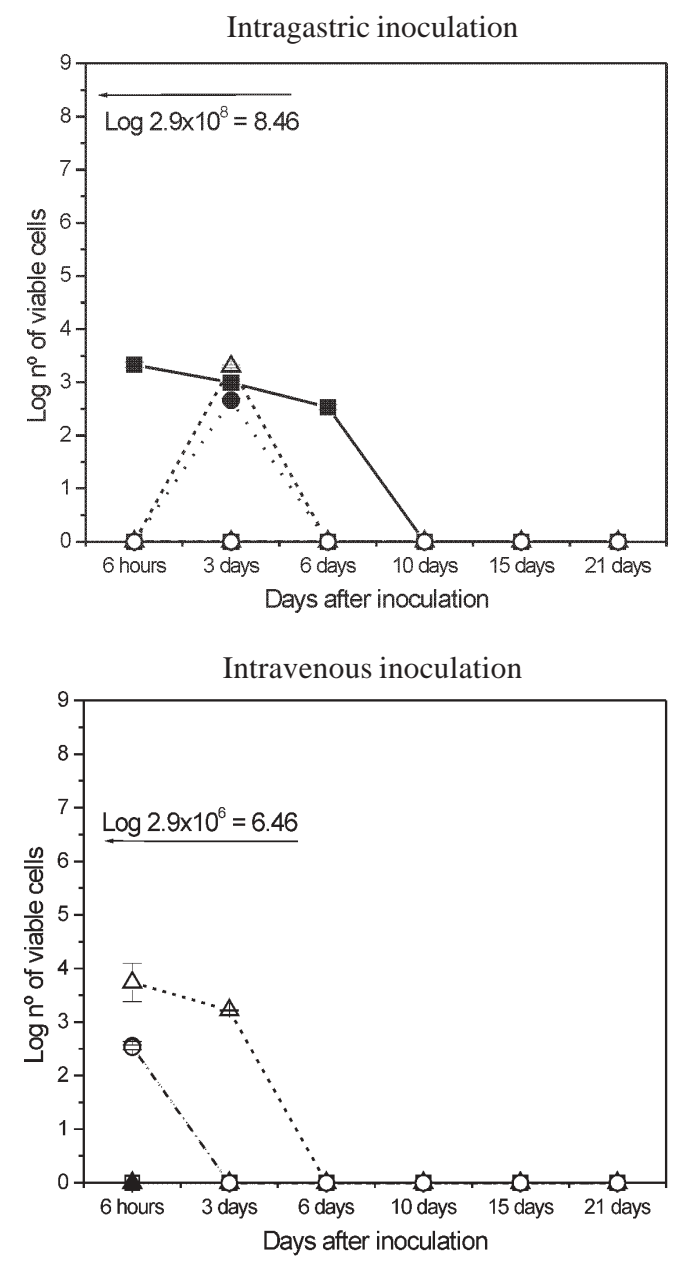

$\begin{array}{lll}\text {. } & \text { Cecal content }-\square \text {. Peyer's patches } \cdots \text { Spleen }\end{array}$

Fig. 2: experimental infection with strain Yp94: Yersinia pseudotuberculosis 2/O:3 not harboring the virulence plasmid and $\operatorname{lcr} F$ gene, but positive for irpl and irp 2 genes, inoculated intragastrically and intravenously into female Swiss mice. 

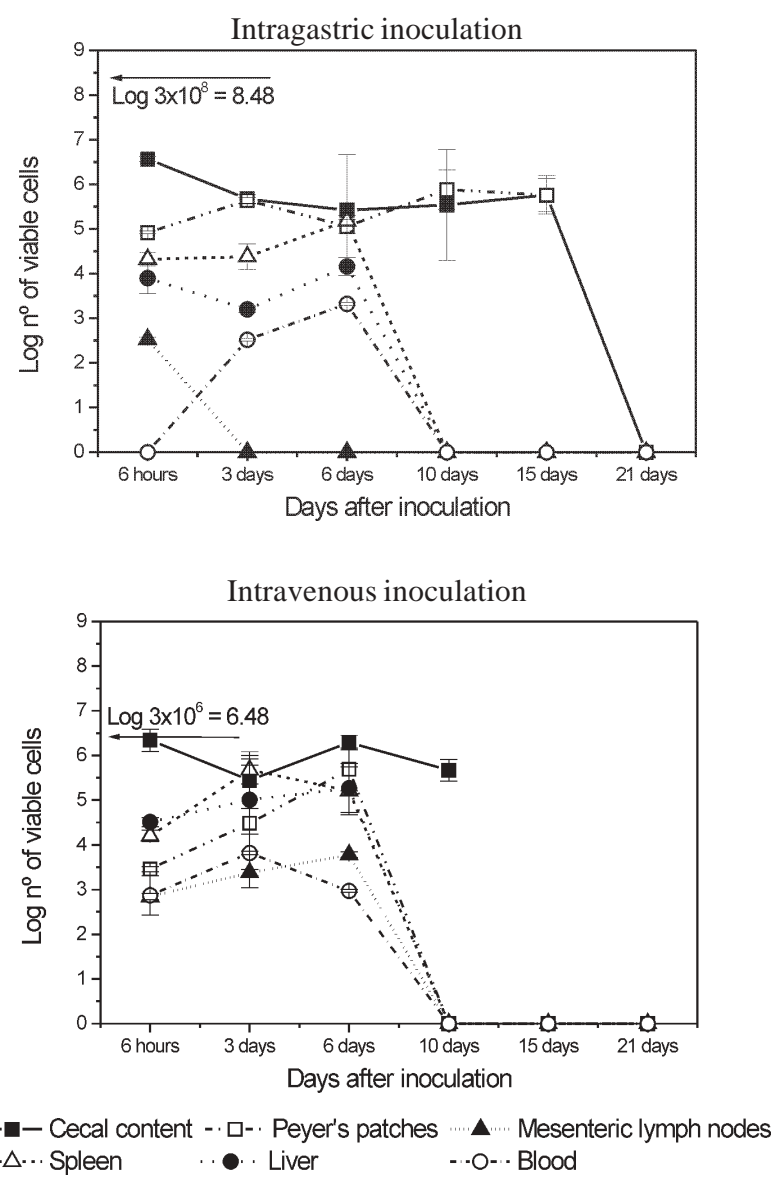

Fig. 3: experimental infection with strain Yp32: Yersinia pseudotuberculosis 1/O:1a harboring the virulence plasmid and positive for $l c r F$, irp1, irp2, psn, IS $100, y b t E, y b t X-y b t S$, and $y b t P-y b t Q$ genes, inoculated intragastrically and intravenously into female Swiss mice.

mid, was not isolated either $6 \mathrm{~h}$ after inoculation or on the 21 st day of infection from any of the sites examined. It caused prostration in animals, but not diarrhea. Macroscopic examination of the spleen, liver and Peyer's patches of the animals sacrificed on the 6th day showed enlargement of these organs and five of them died during the experiment. Six hours after IV inoculation (Fig. 5), bacteria were found only in the spleen, liver and blood, while after 15 days they were found in cecal content, Peyer's patches, and the mesenteric lymph nodes. The experiments were concluded on the 15th day when the five surviving animals were sacrificed, all other animals having died between the 6th and 10th day after infection. After IV inoculation, the animals presented diarrhea and emaciation, apathy and ruffled hair, and enlarged spleen and liver, with macroscopic lesions appearing between the 3rd and 6th day.

\section{DISCUSSION}

The results presented in this study show that the microorganism's ability to invade and multiply in the infected animals is directly related to the presence of the pYV plasmid, regardless of the inoculation route.
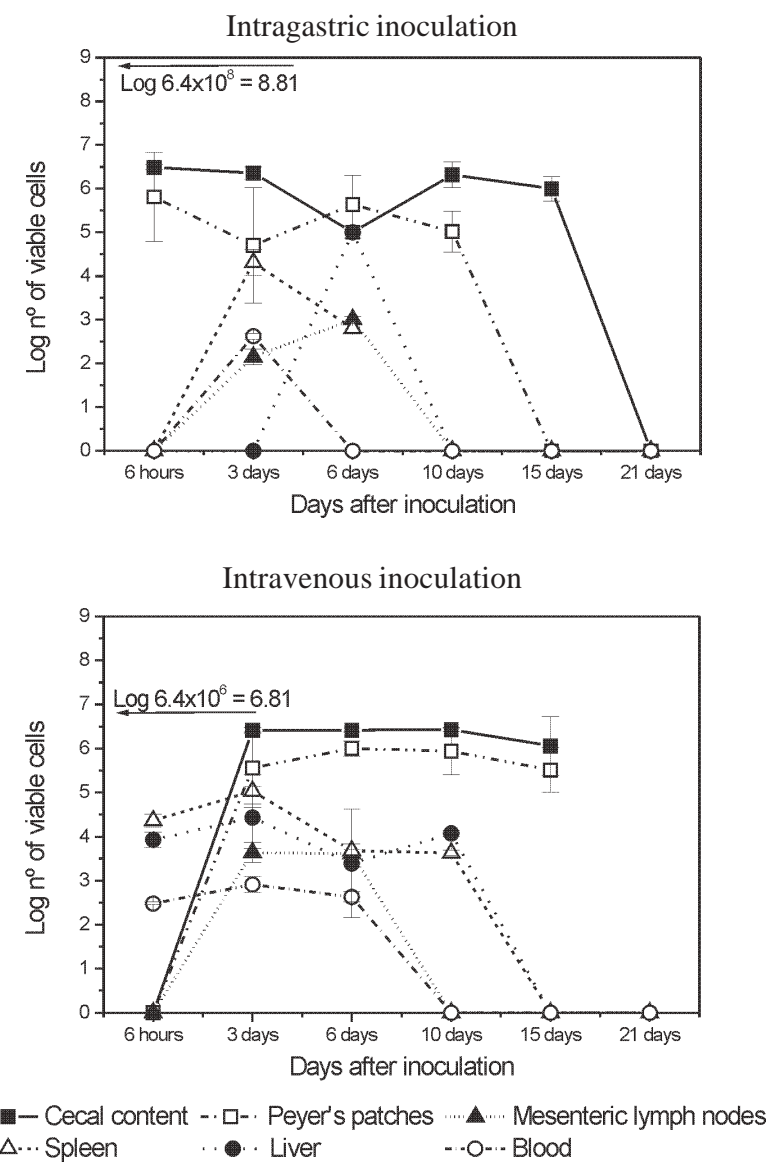

Fig. 4: experimental infection with strain Yp21: Yersinia pseudotuberculosis 2/O:3 harboring the virulence plasmid and positive for $l c r F$, irp1, and irp2 genes, inoculated intragastrically and intravenously into female Swiss mice.

The ability of $Y$. pseudotuberculosis to neutralize the effects of the host's immune system and thus survive and spread through the spleen and liver depends on whether it harbors this plasmid. The genes carried on $\mathrm{pYV}$ express components of the type-III secretion system, including effector Yops molecules (Cornelis et al. 1998). Some investigators (Holmström et al. 1995, Monack et al. 1998) have demonstrated that Yops are responsible for the ability of Yersinia to multiply in Peyer's patches, to invade tissues, and to cause the death of infected mice. However, by means of electron microscopy, Simonet et al. (1990) found evidence that $Y$. pseudotuberculosis strains that lose the pYV plasmid are able to multiply during the early stages of infection in a similar fashion to that of strains harboring the plasmid, probably through the action of the chromosomal virulence factors present.

Two of the five Y. pseudotuberculosis strains used in this study did not harbor the plasmid, although one of these was isolated from a sick animal (Yp36) and the other from a healthy animal (Yp94). Both showed quite similar infection kinetics, not being very invasive and practically not multiplying in the organs of the animals, regardless of the route of infection. 
Intragastric inoculation

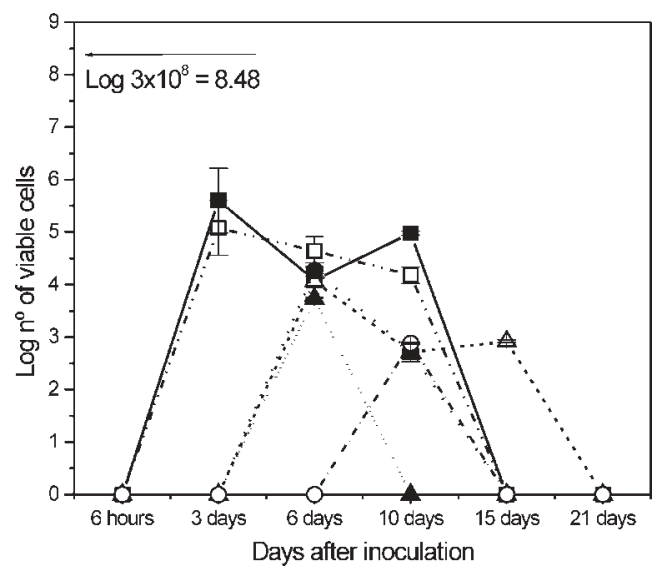

Intravenous inoculation

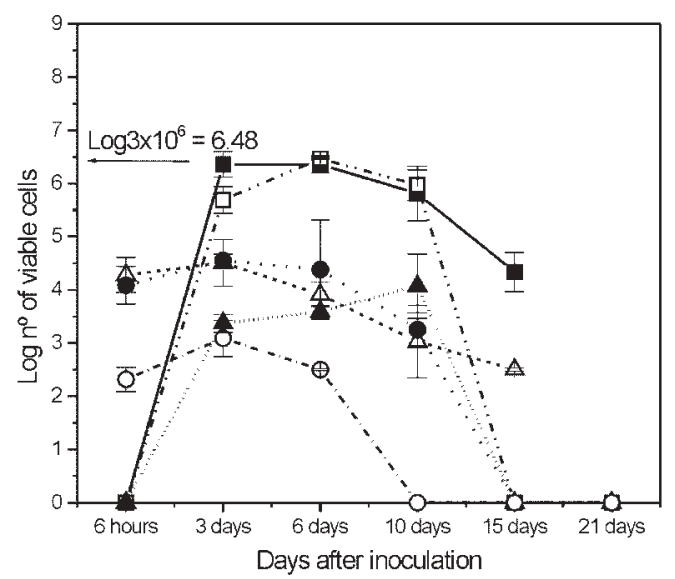

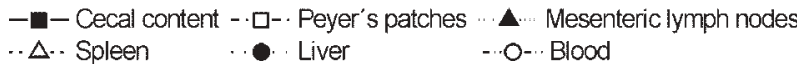

Fig. 5: experimental infection with strain Yp61: Yersinia pseudotuberculosis 2/O:3 harboring the virulence plasmid and positive for $\operatorname{lcr} F$, irp 1 , and $\operatorname{irp} 2$ genes, inoculated intragastrically and intravenously into female Swiss mice.

It should be pointed out that the animals inoculated with strains Yp36 and Yp94, which did not harbor the virulence plasmid, did not show any clinical alterations or any macroscopic lesions in any of the organs examined during the 21 days of the experiment.

The presence of the pYV plasmid in the other strains studied (Yp32, Yp21, and Yp61) caused the infection to develop differently from that caused by plasmidless strains, Yp36 and Yp94, since the mice suffered more severe infection.

The evolution data for in vivo infection showed greatest aggressiveness in the Yp32 strain belonging to serogroup O:1a. This strain induced diarrhea regardless of the route of inoculation and killed all but five of the animals by the 10th day after IV inoculation. This strain presents a complete high-pathogenicity island (HPI), which is related to the strategy of acquiring iron molecules. It is well known that for bacterial pathogens, the successful establishment of disease depends on the abil- ity of the organisms to acquire iron. In Yersinia one of the major differences between strains with low and high pathogenity lies in their ability to capture iron molecules in vivo and thus to disseminate and cause systemic infections (Carniel 1999).

The only strain that presents all genes of HPI was the Yp32. Also it was the only strain able to infect all sites when examined 6 hours after IV inoculation, and all except blood, 6 hours after IG infection. These results are in agreement with those in the literature, since $Y$. pseudotuberculosis O:1a strains are classified as highly virulent (Rakin et al. 1995, Monack et al. 1998).

The other two strains (Yp61 and Yp21), although harboring the virulence plasmid, were less virulent than Yp32, probably because they did not possess a complete HPI. They caused diarrhea after IV but not after IG inoculation. Similar data are reported by Cornelis et al. (1987) in relation to $Y$. enterocolitica; according to them, diarrhea or loose stools are not common features of yersiniosis in mice infected intragastrically with the $Y$. enterocolitica O:8 (American strain), a situation that reflects the human infection, in which fever and abdominal pain without diarrhea are the common clinical manifestations of the disease.

It is very well known that the $\mathrm{LD}_{50}$ for $Y$. pestis and virulent strains of $Y$. enterocolitica and $Y$. pseudotuberculosis is very low for some types of mice, but not for others. Several studies have highlighted differences in the resistance of various mouse strains to intravenous infection with Y. enterocolitica. (Hancock et al. 1986, Heesemann et al. 1993, Autenrieth et al. 1994). By the other hand, Handley et al. (2004) working with different strains of inbred mice related that the animals presented no differences in $50 \%$ lethal dose $\left(\mathrm{LD}_{50}\right)$ following oral infection with $Y$. enterocolitica.

It is important to emphasize that in the present work with $Y$. pseudotuberculosis, the animal model used was female Swiss mice aged 5 to 6 weeks. This model has been used in previous studies to determine the kinetics of infection of various species of Yersinia, including the highly pathogenic $Y$. enterocolitica $\mathrm{O}: 8 \mathrm{WA}$; also the same routes of infection (IG and IV) were used, as well as similar doses: $10^{6}$ cells $/ \mathrm{ml}$ for IV and $10^{8}$ cells $/ \mathrm{ml}$ for IG inoculation (Falcão et al. 1984, Bauab \& Falcão 1991).

The present results also confirm the interdependence between virulence markers located on the pYV plasmid and on the chromosome for the full expression of $Y$. pseudotuberculosis disease, as previously reported by Carniel (2001) and Fukushima et al. (2001).

\section{REFERENCES}

Alonso JM, Bercovier H, Destombes P, Mollaret HH 1975. Pouvoir pathogène experimental de Yersinia enterocolitica chez la souris athymique (nude). Ann Microbiol (Inst Pasteur) $126 B: 187-199$.

Alonso JM, Mazigh D, Bercovier H, Mollaret HH 1978. Infection expérimentale de la souris par Yersinia enterocolitica. Ann Microbiol (Inst Pasteur) 129B: 27-36.

Apfel MIR, Noleto ALS 1991. Virulence of Yersinia spp. strains isolated from non-human sources. Braz J Med Biol Res 24: 777-786. 
Autenrieth IB, Beer M, Bohn E, Kaufmann SH, Heesemann J 1994. Immune responses to Yersinia enterocolitica in susceptible BALB/c and resistant C57BL/6 mice: an essential role for gamma interferon. Infect Immun 62: 2590-2599.

Bauab TM, Falcão DP 1991. Experimental infection of mice with Yersinia strains bearing or not bearing the virulenceassociated plasmid. Contrib Microbiol Immunol 12: 144155.

Brubaker RR 1991. Factors promoting acute and chronic diseases caused by Yersiniae. Clin Microbiol Rev 4: 309-324.

Carniel E 1999. The Yersinia high-pathogenicity island. Int Microbiol 2: 161-167.

Carniel E 2001. The Yersinia high-pathogenicity island: an ironuptake island. Microbes and Infect 3: 561-569.

Carter PB, Collins FM 1974. Experimental Yersinia enterocolitica infection in mice: kinetics of growth. Infect Immun 9: 851-857.

Clark MA, Hirst BH, Jepson MA 1998. M-cell surface Bintegrin expression and invasin-mediated targeting of Yersinia pseudotuberculosis to mouse Peyer's patch M-cells. Infect Immun 66: 1237-1243.

Cornelis G, Laroche Y, Balligand G, Sory M-P, Wauters G 1987. Yersinia enterocolitica, a primary model for bacterial invasiveness. Rev Infect Dis 9: 64-86.

Cornelis GR, Boland A, Boyd AP, Geuijen C, Iriarte M, Neyt C, Sory M-P, Stainier I 1998. The virulence plasmid of Yersinia, an antihost genome. Microbiol Mol Biol Rev 62: 1315-1352.

Falcão DP, Shimizu MT, Trabulsi LR 1984. Kinetics of infection induced by Yersinia. Curr Microbiol 11: 303-308.

Falkow S, Isberg RR, Portnoy DA 1992. The interaction of bacteria with mammalian cells. Annu Rev Cell Biol 8: 333363.

Fukushima H, Matsuda Y, Seki R, Tsubokura M, Takeda N, Shubin FN, Paik IK, Zheng XB 2001. Geographical heterogeneity between far eastern and western countries in prevalence of the virulence plasmid, the superantigen Yersinia pseudotuberculosis-derived mitogen, and the high-pathogenicity island among Yersinia pseudotuberculosis strains. J Clin Microbiol 39: 3541-3547.

Grutzkau A, Hanski C, Hahn H, Riecken EO 1990. Involvement of M cells in the bacterial invasion of Peyer's patches: a commom mechanism shared by Yersinia enterocolitica and other enteroinvasive bacteria. Gut 31: 1011-1015.

Hancock GE, Schaedler RW, MacDonald TT 1986. Yersinia enterocolitica infection in resistant and susceptible strains of mice. Infect Immun 53: 26-31.

Handley SA, Dube PH, Revell PA, Miller VL 2004. Characterization of oral Yersinia enterocolitica infection in three different strains of inbred mice. Infect Immun 72: 1645-1656.

Heesemann J, Gaede K, Autenrieth IB 1993. Experimental Yersinia enterocolitica infection in rodents: a model for human yersiniosis. APMS 101: 417-429.

Holmströn A, Rosqvist R, Wolf-Watz H, Forsberg A 1995. Virulence plasmid-encoded YopK is essential for Yersinia pseudotuberculosis to cause systemic infection in mice. Infect Immun 63: 2269-2276.

Martins CHG, Bauab TM, Falcão DP 1998. Characteristics of Yersinia pseudotuberculosis isolated from animals in Brazil. J Appl Microbiol 85: 703-707.

Monack DM, Mecsas J, Bouley D, Falkow S 1998. Yersiniainduced apoptosis in vivo aids in the establishment of a systemic infection of mice. J Exp Med 188: 2127-2137.

Quan TJ, Meek JL, Tsuchiya KR, Hudson BW, Barnes AM 1974. Experimental pathogenicity of recent North American isolates of Yersinia enterocolitica. J Infect Dis 129: 341344.

Rakin A, Urbitsch P, Heesemann J 1995. Evidence for two evolutionary lineages of highly pathogenic Yersinia species. J Bacteriol 177: 2292-2298.

Revell PA, Miller VL 2001. Yersinia virulence: more than a plasmid. FEMS Microbiol Lett 205: 159-164.

Salyers AA, Whitt DD 2002. Yersinia pestis, the cause of plague and its, relatives. In Bacterial Pathogenesis: a Molecular Approach, ASM Press, Washington, DC, p. 202-215

Simonet M, Richard S, Berche P 1990. Electron microscopic evidence for in vivo extracellular localization of Yersinia pseudotuberculosis harboring the $\mathrm{pYV}$ plasmid. Infect Immun 58: 841-845.

Tsubokura M, Otsuki K, Kawaoka Y, Maruyama T 1984. Characterization and pathogenicity of Yersinia pseudotuberculosis isolated from swine and others animals. J Clin Microbiol 19: 754-756.

Une T 1977. Studies on the pathogenicity of Yersinia enterocolitica. I. Experimental infection in rabbits. Microbiol Immunol 21: 349-363.

Veljanov D, Nikolova S, Najdenski H, Radoucheva T, Kussovski V, Grigoriev I, Ilieva L 1993. Studies on aerosol Yersinia pseudotuberculosis infection of guinea-pigs. Acta Bulg Microbiol 30: 3-10. 